\title{
PROFESSOR PAUL SINGER E A ECONOMIA SOLIDÁRIA ${ }^{1}$
}

\author{
André Ricardo de Souza² \\ UFSCar
}

\begin{abstract}
Resumo
O professor Paul Singer foi um dos principais intelectuais brasileiros, com produção científica amplamente reconhecida, trajetória de vida, da infância à senioridade, marcada por corajosa coerência em importantes processos de construção institucional, militância política e gestão pública. Este artigo aborda especificamente sua contribuição na concepção teórica e construção do universo da economia solidária, desde suas ações na Universidade de São Paulo até a saída da Secretaria Nacional de Economia Solidária. Aspectos de sua personalidade educativa, apontados a partir de convivência pessoal, são destacados em seu grande legado.
\end{abstract}

Palavras-chave: Paul Singer. Processos Educativos. Autogestão. Socialismo. Economia Solidária.

\begin{abstract}
Professor Paul Singer was one of the main Brazilian intellectuals, with widely recognized scientific production, life trajectory, from childhood to seniority, marked by courageous coherence in important processes of institutional construction, political militancy and public management. This article specifically approaches his contribution in the theoretical conception and construction of the universe of solidarity economy, from his actions at the University of São Paulo until leaving the National Secretariat of Solidarity Economy. Aspects of his educative personality, pointed out from personal friendship, are highlighted in his great legacy.
\end{abstract}

Keywords: Paul Singer. Educational Processes. Self-management. Socialism. Solidarity Economy.

\footnotetext{
${ }^{1}$ Dedico este trabalho não só ao professor Paul Singer, mas ao também querido amigo Ademar Bertucci, que foi por muitos anos assessor da Cáritas Brasileira, faleceu em 15 de outubro de 2018 e ao lado do professor compôs a dupla de maiores militantes da economia solidária no Brasil.

2 Professor Adjunto do Departamento de Sociologia da UFSCar 


\section{INTRODUÇÃO}

Paul Israel Singer teve uma longa e bela vida marcada por reconhecimento acadêmico, científico e político. Judeu e austríaco de nascimento, já aos 8 anos, deixou a Europa, que estava em contaminação pelo nazismo, para abraçar junto com sua mãe costureira o Brasil como pátria do coração. Metalúrgico eletrotécnico e liderança sindical, foi um dos condutores da histórica greve dos 300 mil em São Paulo de 1953, além de militante do movimento kibutziano Dror e do Partido Socialista Brasileiro e depois fundador do Partido dos Trabalhadores. Da condição de operário veio a ingressar como estudante na Universidade de São Paulo, formando-se economista, doutorou-se em sociologia sob a orientação do professor Florestan Fernandes em 1966. Ainda naquele ano e no seguinte, fez pós-doutorado em demografia na Universidade de Princeton, Estados Unidos, onde teve contato com o educador da Universidade Estadual de Campinas, Rubem Alves. Após lecionar na Pontifícia Universidade Católica de São Paulo, tornou-se professor titular da Faculdade de Economia, Administração e Contabilidade (FEAUSP) onde recebeu a aposentadoria compulsória aos 75 anos.

Enquanto ainda estudante na USP, formou com os professores assistentes Fernando Henrique Cardoso, José Arthur Gianotti e Fernando Novais, entre outros intelectuais o renomado Grupo de Estudos de O Capital, a grande obra de Karl Marx, que Singer lia em alemão, facilitando tal estudo coletivo. Agindo conjuntamente com Cardoso, Gianotti, Ruth Cardoso, Elza Berquó e outros pesquisadores e pesquisadoras importantes fundou em 1969 o Centro Brasileiro de Análise e Planejamento (CEBRAP). Trinta anos depois, em 1989, veio a assumir a Secretaria de Planejamento da Prefeitura de São Paulo, estando ao lado de dois outros célebres professores: Paulo Freire e Marilene Chauí, no secretariado da prefeita Luiza Erundina, com quem cultivou grande amizade. Posteriormente, entre 2003 e 2016, esteve à frente da Secretaria Nacional de Economia Solidária (SENAES), vinculada ao Ministério do Trabalho e Emprego, durante os governos de Luiz Inácio Lula da Silva e Dilma Rousseff.

Tal é, digamos, uma síntese da rica trajetória deste intelectual com vasta e importante produção literária na área de economia e trabalhos relevantes também para a demografia e as ciências sociais. Suas obras, bem como os pormenores de seus feitos científico-acadêmicos, merecem uma abordagem qualificadamente ampliada, algo que não é meu propósito com este singelo texto. Minha contribuição particular diz respeito ao caminho por ele trilhado a partir da segunda metade dos anos 1990, na construção do universo acadêmico, científico e político denominado economia solidária. 
A história de diversos movimentos econômicos, políticos, artísticos e culturais é marcada pela iniciativa de pessoas que conseguem reunir em torno de si outras mais, também entusiasmadas e tornadas adeptas de sua causa. Tais indivíduos acabam por imprimir em seus movimentos sua marca pessoal, algo explícito no início da empreitada, que ao passar dos anos se desbota, mas às vezes é rememorado e revigorado. Esses líderes cumprem um papel educativo, mediante orientação, estímulo e magnetismo pessoal. O mencionado pedagogo Paulo Freire, bastante admirado por Singer, teve grande influência no desenvolvimento do cristianismo da libertação (LOWY, 2000). Sua principal obra, Pedagogia do oprimido, era uma das favoritas de um jovem padre e professor espanhol chamado José Arizmendiarrieta, que, a partir da formação de uma escola para filhos de operários da pequena cidade basca de Mondragon na Espanha dos anos 1950, viria edificar um internacional complexo cooperativo com o nome daquele município. Embora não tenha atualmente boa parte das feições autogestionárias iniciais, aquela constitui a maior experiência cooperativista já existente (WHYTE; WHYTE, 1998).

Outros clérigos e leigos também seriam protagonistas de mais experiências cooperativistas ao longo século XX, igualmente marcadas em seu nascedouro pelo seguimento de princípios igualitários e democráticos (SOUZA, 2013, p. 40-51). Paul Singer costumava dizer que a economia solidária havia renascido no século $\mathrm{XX}$, tendo sua origem em experiências comunitárias antigas, como a dos primeiros grupos cristãos, descritos nos livro bíblico Atos dos Apóstolos e da experiência indígena chamada República Guarani (LUXEMBURGO, 1986; SINGER, 2002). Mas ele dava ênfase, em termos de raízes da economia solidária, ao que ficou conhecido como o cooperativismo moderno, baseado em princípios voltados para a democracia interna e a perenidade econômica, que teve início em 1844 na cidade inglesa de Rochdale com uma cooperativa de consumo organizada por tecelões ${ }^{3}$. No seu entender, o cooperativismo autogestionário e o sindicalismo operário constituíam formas relevantes de reação de trabalhadores à exploração sofrida no âmbito do capitalismo industrial do século XIX.

Singer afirmava que as experiências de economia solidária, assim como outras de gestão bastante democrática dos recursos públicos, como o Orçamento Participativo, constituíam implantes socialistas na sociedade avassaladoramente capitalista (SINGER, 1998). Em consonância com outros pensadores, sobretudo Rosa Luxemburgo, asseverava que o socialismo

\footnotetext{
${ }^{3}$ Em 1895, ainda no meio operário, foi formada Aliança Cooperativa Internacional (ACI), porém, já nas primeiras décadas do século XX, o cooperativismo adquiriu gradualmente feições empresariais corporativas em detrimento, em detrimento da ênfase na autogestão.
} 
igualitário e necessariamente democrático necessitaria sim de governos condizentes, mas só poderia ser construído socialmente de baixo para cima.

\section{A CONSTRUÇÃO DA ECONOMIA SOLIDÁRIA}

Conheci pessoalmente Paul Singer em 1995, quando eu cursava ciências sociais na USP e ele foi meu professor de Economia 1 na FEA, não tendo havido interlocução exclusiva entre nós durante aquele semestre. No ano seguinte, no contexto eleitoral no município de São Paulo, Singer propôs ao PT a organização dos trabalhadores desempregados de modo a, coletivamente, enfrentarem sua condição. Por sugestão do também economista petista Aluízio Mercadante, o professor Singer adotou definitivamente o termo economia solidária. Em fevereiro de 1997, por coincidência, o encontrei no saguão daquela faculdade e - motivado pela leitura de um artigo dele publicado no dia 12 daquele mês no jornal Folha de S. Paulo, o abordei e ele gentilmente me convidou para prosseguirmos o diálogo em sua sala, algo que levou cerca de duas horas. Havendo alguns obstáculos e interregnos, essa interlocução - marcada para mim por ensino, afeto e estímulo - prosseguiu até três semanas antes de seu falecimento em 16 abril de 2018. Soube dele que tal artigo de jornal, intitulado "Os sem trabalho", lhe ensejou o diálogo também com diversas pessoas mais, para além do ambiente universitário e igualmente interessadas em atuar naquela frente de militância que começava se formar. Sendo procurado por indivíduos tocados por suas ideias, o professor nos incentivou e de algum modo nos aglutinou, dando com isso impulso à construção do que ele entendia ser o movimento da economia solidária.

Foi assim que surgiu em 1997 um pequeno grupo composto por jovens militantes oriundos do curso de ciências sociais da USP e de pastorais sociais católicas da Região Episcopal Brasilândia na periferia norte paulistana, então liderada por dom Angélico Sândalo Bernardino, outro grande incentivador da iniciativa ${ }^{4}$. Recebeu o nome de Núcleo de Ação e Pesquisa em Economia Solidária (NAPES). Certa vez, naquele ano, eu e demais integrantes daquele grupo presenciamos do lado de fora do auditório da FEA lotado Paul Singer interromper a série de respostas, também a professores, após uma palestra dele lá, dizendo que tinha uma reunião "importante": era conosco.

\footnotetext{
${ }^{4}$ Quase vinte anos depois, em 31 de outubro de 2016, tive oportunidade de gravar um vídeo com dom Angélico, Paul Singer e seu amigo o professor Michael Löwy sobre o tema "Religião e Socialismo": https://www.youtube.com/watch?v=v1q-Sis3SjI\&t=162s
} 
Paralelamente à formação do NAPES, o professor Singer conduzia no prédio da Faculdade de Filosofia, Letras e Ciências Humanas da USP o grupo de estudos sobre autogestão que acabou sendo uma das sementes da Incubadora Tecnológica de Cooperativas Populares da USP, surgida em 1998. A ITCP-USP surgiu na esteira de outras incubadoras universitárias que viriam compor uma rede nacional com dezenas de unidades, tendo sido a primeira delas formada na Universidade Federal do Rio de Janeiro (UFRJ) e cuja inspiração havia sido o sociólogo Herbert de Souza, o Betinho na condução de sua campanha chamada de Ação da Cidadania contra a Fome, a Miséria e pela Vida.

Sobremaneira através de sua cunhada, Marilena Nakano, Betinho também incentivou a formação em 1994 de uma entidade aglutinadora de fábricas recuperadas por seus próprios ex-empregados de processos falimentares: a Associação Nacional de Trabalhadores de Empresas de Autogestão (ANTEAG). Vale dizer que uma organização carioca que havia sido formada em 1981 diretamente pelo sociólogo mineiro o Instituto Brasileiro de Análises Sociais e Econômicas (IBASE), viria contribuir para a articulação em prol da política nacional da economia solidária duas décadas depois.

Em uma das conversas com o professor Singer na FEA-USP em 1997 ele contou, com bastante entusiasmo, de sua participação numa feira de cooperativismo popular ocorrida em julho daquele ano na cidade gaúcha de Santa Maria, cujo bispo era outro expoente do cristianismo da libertação: dom Ivo Lorscheiter. Reunindo cerca de duzentos produtores grupais de artesanato, costura e agroindústria, a cooperativa de segundo grau chamada Coopesperanç e liderada pela freira Irmã Lourdes Dill, surgiu a partir de de tal feira, que, por sua vez cresceu de modo a se tornar o evento referência de economia solidária para outros países, não apenas sul-americanos. Trata-se de uma iniciativa apoiada pela Cáritas Brasileira, principal entidade assistencial católica presente em quase todos os territórios nacionais. Desde os anos 1980, a Cáritas dava suporte a pequenos grupos comunitários de geração de renda espalhados pelo país, sobretudo no Nordeste e, também incentivada por Singer, veio a incrementar tal atividade de modo a se tornar a principal organização de apoio a iniciativas desse tipo no Brasil. Sendo eu um sociólogo da religião, orientando na USP pelo professor Reginaldo Prandi, contei com Singer (seu ex-colega do CEBRAP) como um co-orientador informal da minha tese de doutorado sobre a relação entre igreja e economia solidária, defendida em 2006, sendo ampliada e publicada sete anos depois (SOUZA, 2013).

O movimento sindical sempre teve resistência ao cooperativismo devido à contraposição entre a condição de cooperado e a de assalariado. O grande desemprego empurrando à busca de preservação de postos de trabalho remanescentes e a ideia de ampliação 
da "cidadania sindical" compuseram o cenário propício a repensar tal contraposição. Em face disso, o saudoso economista deu também uma contribuição relevante para superar a oposição da Central Única dos Trabalhadores (CUT) às cooperativas de produção. Fazendo interlocução com centrais sindicais de outros países e recebendo recursos de cooperação internacional oriundos da Holanda, a CUT formou a Agência de Desenvolvimento Solidário (ADS), seu organismo próprio voltado para o cooperativismo autogestionário.

Outro conjunto de experiências relevantes em termos de autogestão e que - embora não tenha se identificado claramente como algo próprio da economia solidária devido à sua dinâmica própria de movimento social - foi bastante valorizado por Paul Singer é o das cooperativas agroindustriais do Movimento dos Trabalhadores Rurais Sem Terra (MST), organizados através da Confederação das Cooperativas de Reforma Agráfia do Brasil CONCRAB. Vale mencionar outro conjunto de cooperativas identificadas com um movimento próprio, também valorizadas por Singer e que compõem o universo da economia solidária: as de catadores de resíduos sólidos, que têm como referência o Movimento Nacional dos Catadores de Material Reciclável. Ambos os movimentos - de sem terra e de catadores - têm origens em pastorais sociais católicas.

Nos segundo semestres entre 1999 e 2002, renovando o programa a cada ano, o estimado professor ministrou uma disciplina de pós-graduação na FEA-USP intitulada "Economia solidária resposta à crise do trabalho", um espaço riquíssimo de estudo e debates. Nas aulas, ele conseguia tornar a economia algo simples, indicando claramente que se trata de algo muito importante para ficar apenas nas mãos dos economistas. Foi durante tal disciplina em 1999 que lhe propus e ele, conferindo-me grande honra, aceitou com bastante entusiasmo organizarmos um livro com textos de diversos autores sobre as principais experiências de economia solidária conhecidas por nós até aquele momento e que foi publicado no ano seguinte (SINGER; SOUZA, 2000). Reunindo os melhores trabalhos daquela disciplina de pós, selecionados pelo próprio professor, eu e outros dois ex-alunos organizamos uma coletânea de ensaios que veio a ser publicada em 2003, como uma homenagem surpresa a ele (SOUZA; CUNHA; DAKUZAKU, 2003), por ocasião de seu recebimento da Câmara Municipal de São Paulo do título de cidadão paulistano por iniciativa do então do petista e então vereador Carlos Neder.

Tais livros e outros mais, de relevantes pesquisadores (GAIGER, 2004; CATTANI, 2003), contribuíram para que a economia solidária tivesse aumentada sua visibilidade seu reconhecimento. A obra inaugural no tema em 1998, de Paul Singer e intitulada Uma utopia militante: repensando o socialismo, é também, a meu ver, a mais importante, por sua 
contribuição teórica. Pouco antes de ela ser publicada, começaram a ser formados alguns grupos de representação política voltados para o tema, agregando ativistas de diferentes organizações, com destaque para a Cáritas Regional do Rio Grande do Sul mediante seu Fórum Estadual de Economia Popular Solidária ${ }^{5}$. Na capital paulista, o professor uspiano, eu e outros militantes dessa causa estivemos juntos na formação em 1999 de um fórum municipal desse tipo. Outros fóruns vinham se formando e assim prosseguiram, de modo a contribuírem para fazer com que a proposta fosse assimilada por governos instituídos. Após as prefeituras de Porto Alegre e São Paulo, entre as maiores cidades - todas administradas pelo Partido dos Trabalhadores - a economia solidária se tornaria política pública estadual no governo do também petista Olívio Dutra, através de um contrato com a ANTEAG.

E foi nesse contexto político gaúcho que aconteceu em Porto Alegre, entre 25 e 30 de janeiro de 2001, o primeiro Fórum Social Mundial, considerado um marco na trajetória da economia solidária no país. Começou ali a se formar um grupo de trabalho (GT-Brasileiro) composto pelas entidades nacionais de apoio a inciativas desse tipo, incluindo ainda uma rede gestores de políticas públicas afins. Dois anos depois, Paul Singer publicaria pela Fundação Perseu Abramo o pequeno livro Introdução à economia solidária e Luiz Inácio Lula da Silva, que escreveu a orelha da obra, seria eleito pela primeira vez Presidente da República, impulsionando uma organização política ainda maior do GT Brasileiro junto a fóruns estaduais e regionais de economia solidária. Ademar Bertucci teve um papel fundamental nessa mobilização que acabou culminando na criação da Secretaria Nacional de Economia Solidária (SENAES) que veio a ser chefiada pelo professor Singer no Ministério do Trabalho e Emprego, conduzido por Jacques Wagner. E em Brasília, na mesma semana em que André Singer, então porta voz do presidente Lula, anunciava a oficialização daquele órgão sob o comando de seu pai, foi também efetivada a formação do Fórum Brasileiro de Economia Solidária (FBES).

Resistindo a alguns a revezes, sobretudo durante o governo de Dilma Rousseff, e estabelecendo parcerias com diversos ministérios e órgãos do governo federal, Paul Singer permaneceu à frente da SENAES até abril de 2016, quando Dilma foi afastada da Presidência da República no início do golpe parlamentar que terminaria em agosto seguinte. A permanência semanal do professor em São Paulo propiciou que passássemos a nos encontrar com certa frequência, até seu falecimento dois anos depois.

\footnotetext{
5 Por enfatizar a base, na perspectiva católica da "opção pelos obres", a Cáritas mantém o termo popular, ao se referir à economia solidária (BERTUCCI; SILVA, 2003).
} 


\section{CONCLUINDO: O LEGADO}

Eu e outros amigos e colegas que éramos estudantes na USP - sobremaneira de ciências sociais, psicologia, economia e engenharia da produção - reunidos, orientados e estimulados pelo querido professor, fomos chamados algumas vezes de "os meninos do Singer". Em 24 de abril de 2005, por ocasião de um encontro no auditório de história daquela universidade, alguns de nós, pós-graduandos ainda, formalizamos a criação de uma entidade denominada Associação Brasileira de Pesquisadores de Economia Solidária (ABPES). Passada exatamente uma década, em 19 de junho de 2015, o professor Paul Singer proferiu no Teatro Florestan Fernandes da Universidade Federal de São Carlos (UFSCar) a conferência de encerramento do primeiro congresso internacional organizado pela ABPES, tendo sido sua última conferência, que foi transcrita e publicada no livro A economia solidária e os desafios globais do trabalho, que tive a felicidade de organizar com a amiga docente da UFSCar Maria Zanin (SOUZA; ZANIN, 2017). Em 28 de setembro último, na mesa de encerramento da segunda edição de tal congresso, estive numa mesa que também homenageou o professor, contando com a participação do saudoso Ademar Bertucci. O professor e Ademar eram associados honorários da ABPES.

Tendo sido uma voz corajosamente crítica ao governo Dilma Rousseff ainda enquanto esteve na SENAIS, ele também deixou reflexão importante num pequeno e ainda pouco conhecido livro, decorrente de seminário organizado pelo PT, no qual foi palestrante junto com o economista da Pontifícia Universidade Católica de São Paulo, João Machado, que fora meu colega nas aulas de pós-graduação na FEA-USP sobre economia solidária. Essa publicação, intitulada Economia Socialista, foi prefaciada por uma pessoa de referência para Singer e grande amigo dele, o professor Antonio Candido, que afirmou naquele pequeno texto ser o socialismo uma "bússola ideológica" que necessariamente deve nos orientar. Machado chamou atenção no seminário e no livro para o risco que havia de governos de esquerda encararem o socialismo apenas como uma vaga ideia de sociedade mais justa, sendo o que, infelizmente, acabou ocorrendo nos governos petistas de Lula e Dilma. Singer, por sua vez, afirmou a necessidade da existência do mercado, que segundo ele, pode e deve ser organizado conforme os parâmetros igualitários e democráticos da economia solidária. Deduzo que o mercado é précapitalista e deverá existir na sociedade pós-capitalista ou socialista, sendo a economia solidária um dos caminhos para chegar até ela. 
Brilhante intelectual, decodificador da economia, grande educador e, definitivamente, um militante do socialismo democrático, algo que ao ser buscado, já produz mudanças significativas, conforme pude averiguar nesses anos de convivência com ele, Paul Singer ensinou realmente muito e prosseguirá nos inspirando. 


\section{REFERÊNCIAS:}

BERTUCCI, Ademar Andrade; SILVA, Roberto Marinho. 20 anos de economia popular solidária: trajetória da Cáritas Brasileira dos PACs à EPS. Brasília, Cáritas Brasileira, 2003.

GAIGER, Luiz Ignácio. 2000. Os caminhos da economia solidária no Rio Grande do Sul. In: SINGER, Paul \& SOUZA, André Ricardo de (Orgs.) A economia solidária no Brasil: a autogestão como resposta ao desemprego. São Paulo, Contexto.

LÖWY, Michael. A guerra dos deuses: religião e política na América Latina. Petrópolis, Vozes, 2000.

LUXEMBURGO, Rosa. O socialismo e as igrejas. São Paulo, Dois Pontos, 1986.

SINGER, Paul. Uma utopia militante: repensando o socialismo. São Paulo, Vozes, 1998.

A recente ressurreição da economia solidária no Brasil. In: SANTOS, Boaventura de

Sousa (Org.) Produzir para viver: os caminhos da produção não capitalista. Rio de Janeiro, Civilização Brasileira, 2002.

SINGER, Paul; SOUZA, André Ricardo de (Orgs.). A economia solidária no Brasil: a autogestão como resposta ao desemprego. São Paulo, Contexto, 2000.

SINGER, Paul; MACHADO, João. Economia socialista. São Paulo, Fundação Perseu Abramo, 2000.

SOUZA, André Ricardo de; CUNHA, Gabriela Cavalcanti; DAKUZAKU, Regina Yoneko (Orgs). Uma outra economia é possível: Paul Singer e a economia solidária. São Paulo, Contexto, 2003.

WHYTE, Willian Foote; WHYTE, Kathleen King. Making Mondragón: the growth and dynamics of the Worker Cooperative Complex. Ithaca, ILR Press, 1988. 